\title{
Mediated discourse analysis
}

Book or Report Section

Accepted Version

Jones, R. H. (2014) Mediated discourse analysis. In: Norris, S. and Maier, C. D. (eds.) Interactions, images and texts: A reader in multimodality. Mouton de Gruyter, New York, pp. 3952. ISBN 9781614511175 Available at http://centaur.reading.ac.uk/66504/

It is advisable to refer to the publisher's version if you intend to cite from the work. See Guidance on citing.

Publisher: Mouton de Gruyter

All outputs in CentAUR are protected by Intellectual Property Rights law, including copyright law. Copyright and IPR is retained by the creators or other copyright holders. Terms and conditions for use of this material are defined in the End User Agreement.

www.reading.ac.uk/centaur 


\section{CentAUR}

Central Archive at the University of Reading

Reading's research outputs online 


\title{
Mediated Discourse Analysis 1
}

\author{
Rodney H. Jones \\ City University of Hong Kong
}

in S. Norris and C.D. Maier (eds.) Texts, images and interactions: A reader in multimodality. New York: Mouton de Gruyter.

The world is full of meaning. Written texts surround us in the form of books, newspapers, street signs, tee-shirts, labels on products, and words on the screens of computers and smartphones. We hear tens of thousands of words a day, some directed specifically at us, but most broadcast or overheard. And meaning comes not just from language. Colors, shapes, gestures, sounds smells and tastes fill our environment, communicating everything from traffic regulations to the innermost feelings of our loved ones. Given the cascade of discourse that confronts us in our daily lives, perhaps the most important question a discourse analyst can ask is: 'Where do I begin?' 'How do I know which discourse is relevant and which is not?'

This question has practical value not just for discourse analysts, but for all of us as we make our way through the world. How do we know which texts to pay attention to and which to disregard? It is also of practical value in helping us to understand how to produce discourse. How does a government highway department know where to place a sign, or an advertiser a billboard? How do we know what words to say or write, what gestures or sounds to make, so they have their intended effect and don't get lost in this deluge of discourse? In other words, how do we know what to pay attention to, and how do we know how to get and keep the attention of others?

The modern supermarket is a good example. As soon as we enter, multiple forms of discourse vie for our attention. Rows and rows of products in colorful packages covered with pictures and written text surround us. Signs advertise items on sale. Verbal announcements emanate from the PA system over the sound of violin versions of old Beatles songs. Kids scream to their parents, who squint at their scribbled shopping lists. Teenagers stocking shelves wear badges with their names on them. Cash registers beep and flash numbers. Currency, credit cards, and receipts change hands. Customers are told to 'have a nice day'. This discursive environment presents challenges to customers as they navigate their way through the store, trying to complete their shopping, to store managers, trying to decide where to place items on the shelves, to food manufactures and distributors, trying to design packages that will catch the eyes of customers, and to legislators trying to determine how to best to regulate what kind to discourse should appear on such packages in order to help customers make informed choices and prevent food manufacturers and distributors from misleading the public.

\footnotetext{
${ }^{1}$ Research for this chapter was made possible by the General Research Fund Grant 'The Discourse of Food Labeling in Hong Kong: Public Policy and Discursive Practice' (\#CityU144110) from the Hong Kong Research Grants Council.
} 
It is problems like this that mediated discourse analysis, an approach to discourse developed by Ron and Suzanne Scollon beginning in the late 1990's (Scollon, 1998; 2001; Scollon \& Scollon, 2004), attempts to address. It does so first and foremost by shifting our focus away from discourse, and on to the actions people use discourse to take. The only way to determine which discourse is worth analyzing, MDA argues, is to first understand what people are doing -whether it is looking for something to eat for dinner, stocking a supermarket shelf, or complying with government regulations regarding nutritional labeling and then to attempt to determine what role discourse plays in these actions.

\section{Mediated action}

The unit of analysis for the mediated discourse analyst is not the word, or the sentence, or the text. Nor is it the image, the gesture or the sound. It is the action which makes use of the word, sentence, image, gesture or sound to get done. Words, sentences, texts, images, gestures and sounds are not of much relevance unless they are in some way involved in actions. At the same time, actions cannot be accomplished without the use of things like words, sentences, texts, images, gestures and sounds, as well as other cultural tools such as supermarket shelves, cash registers, barcode scanners, and cardboard boxes. In other words, all actions are mediated through some kind of cultural tools. Therefore, the real unit of analysis for mediated discourse analysts is not just the action, but the mediated action.

The roots of this approach come from the work of the Soviet psychologist Lev Vygotsky (1981), who sees all action in the world as mediated by 'ciltural tools' which have the effect of either amplifying or constraining those actions. The notion of mediation was important for Vygotsky insofar as it provided a link between social and cultural processes and individual mental processes. Because mental functioning is carried out by meditational means provided by the society, all thought is essentially social. At the same time, individuals appropriate and adapt meditational means for particular concrete purposes. Therefore, the relationship between individual consciousness and the mediational means provided by society is always dialectical, meditational means acting to both afford and limit actions, and individuals constantly adapting mediational means to fit the contingencies of particular circumstances and goals (Wertsch, 1994). What mediated discourse analysts are interested in is the interplay between social actors and cultural tools (including discourse) as it is expressed in action.

\section{Sites of engagement}

When we speak of mediated actions we do not do so in an abstract, decontextalized sense. We do not, for example, speak of the action of choosing a product from a supermarket shelf, for this action is very differnt depending on what the product is, who is doing the choosing, the particular supermarket in which the choosing takes place, and a host of other conditions. Every action is unique and 'unreproducible', taking place at a single point in history at which particular people, particular cultural tools, particular motivations and particular causes and conditions meet. We call this point the 'site of engagement' for an 
action.

Many discourse analysts speak of the importance of 'context' - the conditions that surround a text or utterance, but the 'site of engagement' for an action is not the same as the 'context' of a text. It does not merely 'affect' how the action might be carried out or interpreted. It is what makes the action possible in the first place. Scollon defines a 'site of engagement' as a 'window that is opened up through the intersection of social practices and meditational means (cultural tools) that make that action the focal point of attention of the relevant participants' (2001:4). There are several key concepts in this definition, the most important being the 'attention of the relevant participants'. 'Sites of engagement' are created not just through the physical presence of tools, actions and people at a particular place at a particular time, but rather through the 'attention' or 'engagement' of the people involved. The same configurations of tools at the same moments in time and the same points in space may for some people function as sites of engagement for particular actions, whereas for others they may not.

What determines how people focus their attention is a complex question. Attention is partially determined by cultural tools themselves (including what the Scollons in their 2004 book call 'discourses in place'). As scholars of multimodality (Norris, 2004; Kress and van Leeuwan, 1996) have pointed out, configurations of modes and media have a lot to do with this: the placement of objects in images, the use of color and fonts, the posture and gaze of social actors all contribute to the way attention is channeled. Attention is also a product of what the Scollons (after Goffman, 1983) call the 'interaction order', the relationship among participants that is created as they negotiate the ongoing process of giving and getting attention that constitutes social encounters. The final thing that determines how people 'engage' with particular cultural tools to perform mediated actions has to do with the people themselves, the degree of familiarity they have with the cultural tools at hand and the kinds of actions they are accustomed to performing - what the Scollons refer to as the 'historical bodies' (Nishida, 1959) of the social actors.

\section{Social practices and historical bodies}

Although the focus of mediated discourse analysis is on situated, 'real-time' mediated actions, it is difficult to understand these actions without taking into account how they fit into the fabric of people's experience and the cultures in which they live. Most of the actions that we perform in the course of a day, actions like choosing products from supermarket shelves, queuing at check-out counters, swiping credit cards, and all of the other actions that are part of grocery shopping, are things that we do on a regular basis. In fact, we are sometimes so accustomed to doing these actions that they have become more or less automatic: they have become 'practices'.

What mediated discourse analysts mean by 'practices' is actions or 'chains of action' that have become 'practiced', that have become submerged into the 'historical body' of the social actor. The notion of 'practice' links the individual 
action to a whole history of learning and doing within the mind and body of the individual. It also links the individual action to other actions, since practiced actions rarely occur alone, but usually form part of larger social practices. The action of shaking someone's hand is part of the social practice of greeting. The action of swiping your credit card is part of the social practice of paying. Finally, the notion of practice links individual actions to the groups of people societies and cultures who practice these actions and who recognize one another as members by the actions they perform. So, although every time we choose a product from a supermarket shelf, we are performing a unique, irreducible and unrepeatable action, we feel like we are doing something that we have done before, and people observing us can recognize and perhaps label what we are doing. They might even be able to tell from how we are doing it whether or not they are a 'seasoned shopper' or a member of the family who usually does not do the shopping but has been called upon to pick up a forgotten item on the way home from work.

\section{Itineraries and resemiotization}

As I said above, the way mediated discourse analysts go about deciding what discourse to analyze is by determining the relevant actions and determining which discourse plays a role in the accomplishment of those actions. It should be clear from the discussion above, however, that the task of determining the relevant actions at a particular site of engagement is neither simple nor straightforward. For one thing, any given site of engagement may involve multiple social actors using the same cultural tools to perform very different actions. As a customer chooses a product from a supermarket shelf, a store clerk might be stocking products on the same shelf. Second, even a particular social actor my be engaging in multiple activities at once: at the same time he is choosing a product the customer may be talking on his mobile phone to his wife. The thing that makes this relationship between actions and meditational means most complicated, however, is the fact that every action is part of a long history of actions involving multiple social actors and multiple meditational means. The moment the customer chooses a product from the supermarket shelves is not just part of a longer scale action of a shopping trip, but part of a lifetime of shopping and cooking and consuming food in which all sorts of other people including family members, doctors, advertisers, may all be implicated. And the moment of the store clerk placing the product on the shelf is also part of a long chain of actions involving people like farmers, factory workers, and business executives.

Every social action takes place at the intersection of multiple itineraries of discourse and action (Scollon, 2008) calls. Along these itineraries social actors appropriate various meditational means to take actions which in turn give rise to new meditational means which allow them to take future actions, and through this process selves ('historical bodies') are created, social identities are claimed and imputed, and societies and cultures are produced and reproduced. Iedema uses the term 'resemiotization' to describe this process. What he means by resemiotization is that, as we take action, the meditational means that we use to take those actions change: Conversations between a husband and wife, for 
example, are transformed into shopping lists which are later transformed into products purchased at the supermarket, which in turn are transformed into meals, which (if you want to get technical) are transformed into glucose which fuels the bodies of these social actors to have further conversations, make further lists, and take further journeys to the supermarket.

But meditational means are not the only things that change. Actions and social actors also change as actions along these itineraries are submerged into the 'historical bodies' of participants, becoming 'practices'. The first time I choose a particular item from the supermarket shelves is not the same as the second time or the third time. Many of the meditational means that were very important the first time I bought it - things like its price tag and list of ingredients - are no longer relevant to the accomplishment of the action. That is not to say that the price and ingredients are not important, but the action of determining this information has become part of my 'historical body' and fused with the practice of buying the item to the extent that they do not demand conscious attention to any text, unless, of course, the price or ingredients change for some reason, in which case I might find this practice somehow interrupted.

It is often at these moments when we find our practices 'interrupted' that their real complexity becomes most obvious to us. The multiple chains of action that were so tightly bound into a social practice suddenly unravel, revealing themselves to us. This insight is at the heart of the 'breaching experiments' of the ethnomethodologist Harold Garfinkle (1991), who believed that the best way to understand how people 'do being normal' was to try to poke holes in the fabric of everyday life and observe how people worked together to tie the loose threads back together. It is, however, really not necessary to stage such occurrences. They happen all the time as social actors adjust their actions to the constantly changing convergences of people, tools and social practices that confront them.

\section{Popcorn, movie stars and regulatory discourse}

An example of this can be seen in my own act of choosing a box of Newman's Own Oldstyle Picture Show Microwave Popcorn from a shelf in a supermarket in Hong Kong where I live. This purchase is inextricably tied up with my own particular set of practices around shopping, popcorn eating and movie watching. My partner and I have becoming accustomed to spending our Friday evenings watching a movie on our big screen television, and making a bowl of popcorn has become an expected part of that practice. The practice of eating popcorn while watching movies is of course not unique to us, but has a long history going back to the Great Depression when cinema owners, watching their profits from ticket sales decline, started to sell candy and other snacks in their theaters, and to World War II, when sugar rations resulted in popcorn replacing candy at theater concessions stands. The migration of this practice into people's homes, including my own, can be traced back to other chains of technological development including the invention of 'home theaters' and microwave ovens. 


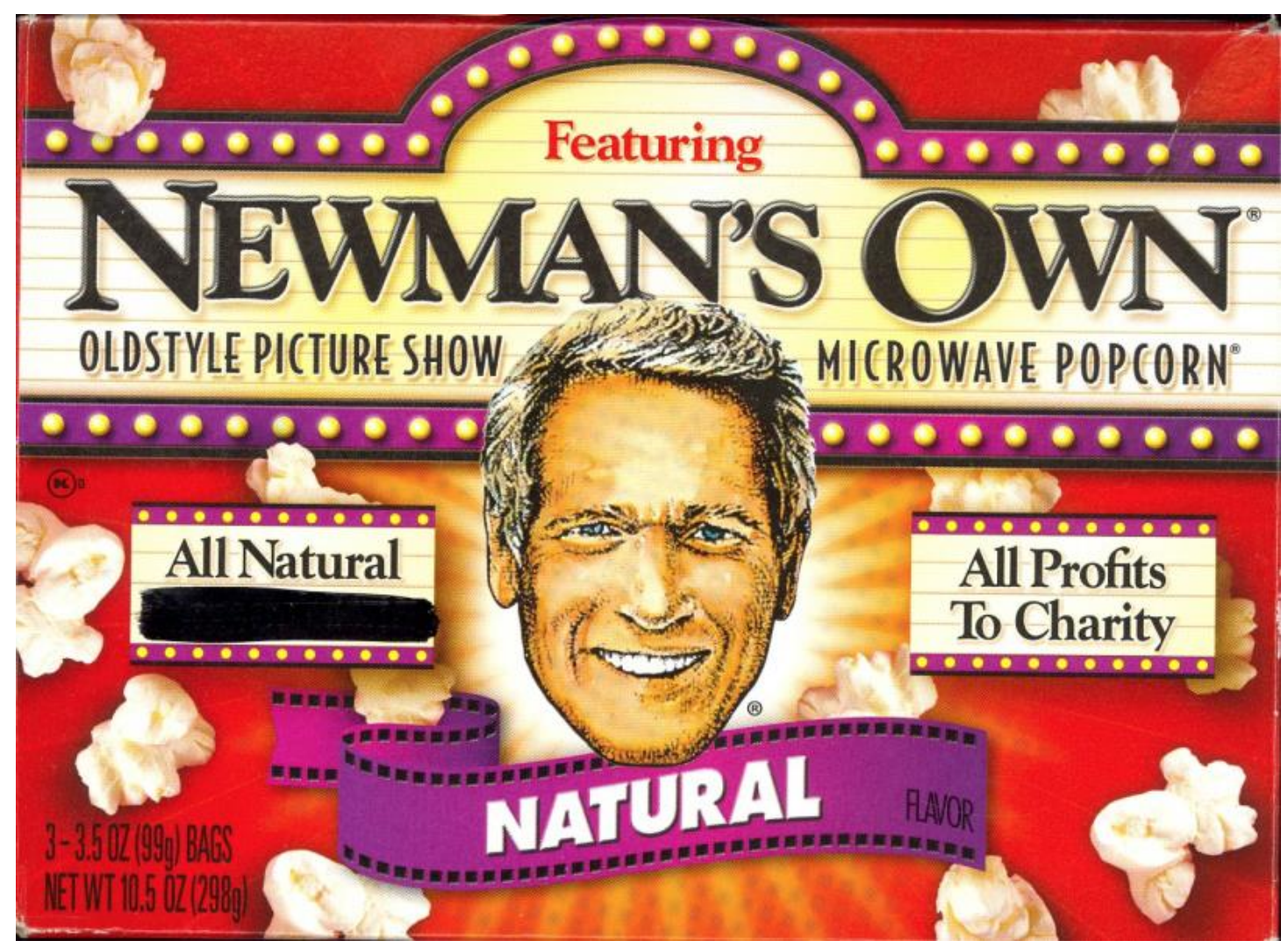

Why I choose this particular brand is slightly harder to unravel. Part of it has to do with the kind of inertia that often accompanies purchasing behavior - I buy this brand because, for as long as I can remember, I have bought it. Part of it has to do with my own 'historical body', the fact that I grew up watching Paul Newman movies, that I'm a Democrat and Paul Newman has always supported liberal causes, the fact that I prefer savory snacks to sweet ones, and a host of other practices and preferences that have become deeply sedimented in my 'historical body'. Also relevant here is the itinerary of discourse and action that led to Paul Newman himself finding his face on a box of microwave popcorn, an itinerary that began with his birth in Shaker Heights, Ohio in 1925, extends through a successful acting career, to 1982 when he stared the Newman's Own line of food products, chiefly as a way of earing money for charities for seriously ill children. Finally, this box of popcorn would not be available for me to choose were it not for the itineraries that led up to it being placed on this particular shelf, itineraries that stretch back to cornfields in Iowa, company board rooms in Westport, Connecticut, and factories in China.

The point is that there are multiple itineraries of discourse and action on many levels from the cultural to the corporate to the personal that conspire to drive the action of me reaching for this package and dropping it into my shopping basket, itineraries that I am not fully conscious of but nevertheless are inseparable from that momentary action and how it gets done. Although most of the chains of action that converge at this moment are deeply submerged in my historical body and into the practices and architecture of the supermarket, the corporate structure of the company that manufacturers the product, and the culture of popcorn eating movie watchers everywhere, if pressed, I and most 
other shoppers could unravel these chains, could, for example, explain why we are buying this particular brand or venture a guess as to why Paul Newman is selling it. The reason for this is that we are not separate 'historical bodies' choosing a box of popcorn, but rather members of a broader 'community of practice', a community that is bound together by thousands of banal practices like movie going and popcorn eating and supermarket shopping.

Most discourse analysts confronted with this package of popcorn would focus on the strategic use of language and other modes: They might for example point out the interdiscursivity on the front of the package which shows an old style movie marquee in which the name of the product appears like the name of a movie. They might point out the intimacy created by the headshot of Paul Newman gazing directly out at the viewer and smiling. They might point out the grammatical construction of phrases like 'No Trans Fats' and 'All Profits to Charity', especially how processes are elided. They might point out the how the words on the package like 'oldstyle', 'natural' and 'charity' (as in 'All Profits to Charity') go together to reproduce a certain ideology that resonates with customers like me who grew up in the $60 \mathrm{~s}$ in the US. They might also turn their attention to issues like font and color, pointing out that the word 'Natural' is printed in bold white font against a purple background, as opposed to the word 'flavoring' to the right of it, printed in a harder to see small, dark font, and how this might potentially mislead customers.

The problem with such an analysis is that it would totally ignore all of those itineraries mentioned above. Gone would be the movie theater concessions stands, the microwave ovens, and the Iowa farmers without which this package would not have been possible. And, most important, gone would be all of the actions in my life that led up to me choosing this product, an itinerary of discourse and action in which the grammar and font of the words on the package are rather peripheral.

In fact, much of the communicative work of the discourse on this package play no role at all in the action of me plucking it from the supermarket shelf. The only really relevant thing about the colors, fonts, words and smiling face of Paul Newman for me at this moment is that they make it recognizable as the same product that I have bought before. In fact there are large parts of this text that I have never read. I've never read the ingredients or the nutritional information on the side of the box (maybe because somewhere deep down I trust Paul Newman), and I've never, until recently, read the additional promotional paragraph printed on the bottom of the box, which reads:

$$
\begin{gathered}
\text { Top-of-The-Crop } \\
\text { Taste. No } \\
\text { Trans Fats. No } \\
\text { Hydrogenated Oils! } \\
\text { It's our great, } \\
\text { crispy, fresh tasting } \\
\text { popcorn without }
\end{gathered}
$$


the trans fats and

hydrogenated oils.

It's deliciously

all natural and

pops to perfection

in two to five minutes.

A diligent discourse analysts would not doubt have included this passage in her analysis, and there is plenty to analyze here, including more literary uses of language like rhyme and alliteration (Carter, 2004). But as a shopper, this text was completely invisible to me until the last time I went searching for the product and found it altered, portions of it redacted with black magic marker.

\author{
Top-of-The-Crop \\ Taste. \\ yydrogenated Oils! \\ It's our great, \\ crispy, fresh tasting \\ popcorn \\ and \\ hydrogenated oils. \\ It's deliciously \\ all natural and \\ pops to perfection \\ in two to five minutes.
}

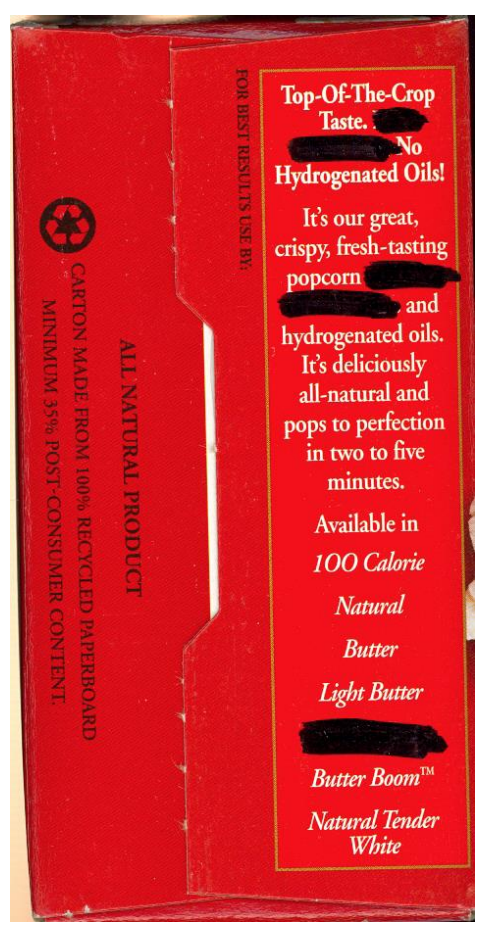


Of course, there is a lot about this new text that is problematic from the point of view of discourse, not least of which is the fact that now it 'means' something totally different than it did before. Before I was buying 'fresh tasting popcorn without ... hydrogenated oils', and now I am buying 'fresh tasting popcorn... and hydrogenated oils'. This in itself, however, (since I have very little knowledge of hydrogenated oils) is not nearly as important as the physical presence of black marks on the package, the physical fact that the product package has been altered by somebody other than Paul Newman or his employees.

Suddenly a piece of discourse that I could safely keep in the background when purchasing this product has been pushed into the foreground, demanding that I take some kind of action with it. But, not understanding the hidden chain of actions that led to these words being hidden, I do not know what action to take. What is important here, what has suddenly disrupted my popcorn purchase, is not discourse per se, but action, the action of somebody somewhere taking a black magic marker and defacing this package. This 'frozen action' (Norris, 2004) embodied in these black marks on the package is enough to interrupt my purchase, to make me consider buying something else instead.

There is, in fact, nothing sinister going on here. The black marks on this package are the result of an itinerary of discourse and action that can be traced back to the passage of a new Food and Drug Composition and Labeling Regulation by the Hong Kong Legislative Council in May 2008, which imposes strict new rules about what can and cannot appear on food labels. Among these is the rule that in order to make the claim 'zero trans fat', a product must fulfill three conditions: 1 ) it must contain no more than .03 grams of trans fats per 100 grams; 2) the sum of trans fats and saturated fats must not exceed 1.5 grams per 100 grams; 3 ) the sum of trans fats and saturated fats must not contribute to more than $10 \%$ of the energy. The fact is, Newman's Own Microwave Popcorn, while actually containing 0 trans facts, contains 6.6 grams of saturated fat per 100 grams, and therefore is not legally permitted to bear the claim 'zero trans fats' (despite the fact that the amount of trans fats in the product equals zero).

The fact that this regulation is rather confusing, however, is not the main problem here. The problem comes in the actions that must be taken to comply with the regulation. Since Hong Kong is such a small market, few major food manufactures are willing to change their packages to comply with these unique rules. Therefore, shopkeepers and supermarket employees are forced to alter packages before they put them on the shelves to avoid falling foul of the law. Once the package finds its way onto the shelves ready for me to reach for it, all of those actions of legislation, regulation, and compliance have become invisible. All that is left are the black marks. The problem is not that I don't know what the words mean, but that I don't even know what the words are.

The goal of the government was to help me make healthy choices about my diet. However, the result is the opposite. Not knowing what is behind those black marks, I immediately become suspicious of Paul Newman and decide to choose another snack item, one with no unsightly black marks because the 
manufacturer of this particular item, chock full of trans fats, has chosen not to make any claims to the contrary. And so I trade in a healthy item for a less healthy one, perhaps beginning a new itinerary leading up to possible heart disease in my later years.

The point I'm trying to make here is that the real problem with this text is not so much that I can't figure out what it means as it is that I can't figure out what it does. What interrupts my practice of popcorn buying, steering it in a new and dangerous direction, is not discourse per se, but the convergence of multiple itineraries of discourse and action, many of which, like the blacked out words, are invisible to me. Not only would analyzing this discourse divorced from the actions it is used to take not help me much in understanding this text, but it is this focus on discourse (meaning) at the expense of considering how it is used to take action that is, in fact, the problem here. In its effort to protect me from the non-existent trans fats in this product, the Hong Kong government has focused only on the words and their 'technical' meanings without considering the complex chains of actions in which these words (and their disappearance) are implicated.

\section{Conclusion}

Mediated discourse analysis is designed to help people understand practical problems in the real world. Often the way to do this is not to focus on discourse, but to consider the chains of actions that discourse is part of. Sometimes, in our efforts to solve problems by altering discourse alone, we end up creating bigger problems. There is no denying that food manufacturers sometimes try to deceive us, and governments must do their best to help prevent that. But simply changing the discourse on food labels is not enough to interrupt the complex and sometimes insidious itineraries of discourse and action that result in the products we find on our supermarket shelves. A better way to address social problems might be to find ways of making these itineraries more visible, and so making the social actors involved in them more accountable. Such an agenda would also involve helping people to make their own itineraries of shopping and eating more visible to themselves and others, and to become more conscious of how even tiny, banal actions of choosing particular products are part of larger social practices, some of which promote health and social justice, and some of which do not. Social change comes not from changing our discourse - it comes from changing our actions. 


\section{References}

Carter, R. (2004). Language and creativity: The art of common talk. New York: Routledge.

Garfinkel, H. (1991). Studies in ethnomethodology. Oxford: Polity Press.

Goffman, E. (1983). The interaction order: American Sociological Association, 1982 presidential address. American Sociological Review, 48(1), 1-17.

Kress, G. R., \& van Leeuwen, T. (1996). Reading images: The grammar of visual design. London: Routledge.

Nishida, K. (1959) Intelligibility and the Philosophy of Nothingness, Tokyo, Maruzen Co. Ltd.

Norris, S. (2004). Analyzing multimodal interaction: A methodological framework. London: Routledge.

Scollon, R. (1998). Mediated discourse as social interaction: A study of news discourse: Longman.

Scollon, R. (2001). Mediated discourse: The nexus of practice. Oxford: Routledge.

Scollon, R. (2008). Discourse itineraries: Nine processes of resemiotization. In V. K. Bhatia, J. Flowerdew \& R. H. Jones (Eds.), Advances in discourse studies (pp. 233-244). London: Routledge.

Scollon, R., \& Scollon, S. (2003). Discourses in place : language in the material world: Routledge.

Scollon, R., \& Scollon, S. W. (2004). Nexus analysis: Discourse and the emerging internet. London: Routledge.

Vygotsky, L. S. (1981). The instrumental method in psychology. In J. V. Wertsch. (ed.) The concept of activity in Soviet psychology. Armonk, NY: M. E. Sharpe, pp. 134-143.

Wertsch, J. V. (1994). The primacy of mediated action in sociocultural studies. Mind, Culture and Activity 1 (4): 202-208.

Suggestions for Further Readings

Norris, S., \& Jones, R. H. (Eds.). (2005). Discourse in action: Introducing mediated discourse analysis. Abingdon: Routledge. 
Bio Note

Rodney H. Jones is an Associate Professor in the Department of English at City University of Hong Kong. His research interests include health communication and digital literacies. He is co-editor (with Sigrid Norris) of Discourse in action: Introducing mediated discourse analysis (Routledge, 2005) and author of Health and risk communication: An applied linguistic perspective (Routledge, 2013).

Correspondence Address:

Department of English

City University of Hong Kong

8/F Run Run Shaw Creative Media Centre

Kowloon Tong

Hong Kong

enrodney@cityu.edu.hk 